\title{
SINERGIA
}

REVISTA DO INSTITUTO DE CIÊNCIAS ECONÔMICAS, ADMINISTRATIVAS E CONTÁBEIS (ICEAC)

\section{A GOVERNANÇA PARTICIPATIVA NA GESTÃO DE RECURSOS HÍDRICOS NO BRASIL: UMA ANÁLISE DA REALIDADE DO ESTADO DA BAHIA}

\author{
ELVIA FADUL \\ FABRICIO TERSO VITORIA \\ LUCAS SANTOS CERQUEIRA**
}

\begin{abstract}
RESUMO
Este artigo objetiva avaliar o processo participativo na gestão de recursos hídricos por comitês de bacias hidrográficas, analisando comitês brasileiros. A Lei № $9.433 / 97$ definiu a gestão desses recursos baseada na integração, descentralização e participação. Pesquisas têm mostrado fragilidades no funcionamento da maior parte desses comitês, sobretudo aqueles localizados na região nordeste do país. O foco deste trabalho é avaliar criticamente os mecanismos do processo participativo no âmbito desses organismos na Bahia. Trata-se de um estudo descritoexploratório e de abordagem qualitativa. Para as análises foram utilizados dados das atas de reunião, baseando a discussão na proposta de Arnstein $(1969,2002)$ que cria uma tipologia com oito níveis de participação. Os resultados indicam que, apesar das mudanças positivas trazidas pela Lei, os comitês ainda apresentam dificuldades operacionais e de exercício da governança participativa. Essa participação tem sido limitada pelo governo central, podendo o envolvimento dos participantes chegar, no máximo, ao degrau da pacificação.
\end{abstract}

Palavras-chave: Participação Social. Água. Recursos Hídricos. Comitês de Bacia. Cidadania

\section{ABSTRACT}

This article aims at assessing the participatory process on water resources management by river basin committees, analyzing Brazilian committees. Law No. 9,433/97 has defined the management of these resources based on integration, decentralization and participation. Research has shown weaknesses in the operation of most of these committees, particularly those located in the northeastern region of the country. The focus of this work is to evaluate critically the participatory mechanisms in the context of these organisms in Bahia. This is a study describedexploratory and qualitative approach. For the analyses were used data from the meeting minutes, based on the discussion in the proposal of Arnstein $(1969,2002)$ that creates a typology with eight levels of participation. The results indicate that despite the positive changes brought by law the committees still have operational difficulties and the exercise of participatory governance. This participation has been limited by the central Government, and the involvement of the participants get, at most, the step of pacification.

Keywords: Social Participation. Water. Water resources. Basin Committees. Citizenship.

Recebido em: 07-02-2017 Aceito em: 07-07-2017

\section{INTRODUÇÃO}

O envolvimento de cidadãos e organizações da sociedade na formulação de políticas públicas e na gestão pública transformou-se, no Brasil, após o período de abertura democrática, seguido do processo de reforma do Estado, em um quase modelo de administração pública. Esse fenômeno político e social de envolvimento não é novo, mas implica um processo de transformação das relações entre Estado e sociedade, de redefinição de espaços, de papéis e de funções, e do deslocamento de poder em processos decisórios.

Essa onda, ou tendência, tem suas origens tanto em iniciativas do próprio Estado, tais como a criação de canais formais de participação, como da própria sociedade, na busca de mecanismos que lhe permitam assumir a condução de seus interesses coletivos para a satisfação de suas necessidades fundamentais. No que se refere à sociedade, o que tem motivado essa onda de participação é, principalmente, a ausência e/ou ineficiência do Estado na provisão e prestação de serviços públicos, o que resulta na ampliação das demandas não atendidas da população e, consequentemente, na busca por serviços de melhor qualidade.

\footnotetext{
"Doutora em Urbanismo pela UPEC - Université Paris-Est Créteil Val de Marne. Atualmente é Coordenadora do PPGA - Programa de Pós-Graduação em Administração na Universidade Salvador - UNIFACS.

${ }^{*}$ Mestre em Administração - UNIFACS. Atualmente Professor na Universidade Salvador - UNIFACS.

"Woutor em Análise Desenvolvimento Regional e Urbano pelo PPDRU na UNIFACS. Mestrado em Administração Estratégica pelo PPGA na UNIFACS, com bolsa CAPES. Atualmente é professor Assistente na Universidade Federal do Rio Grande (FURG)
} 
Há ainda, em algumas sociedades, o sentimento de empoderamento, de construção da cidadania e de promoção do protagonismo da sociedade como fator de mobilização para a participação. Em países desenvolvidos, essa ampliação em processos participativos, requerida pela sociedade, surge, também, como uma reação à dominação e excessiva centralização que o Estado imprime sobre a vida dos cidadãos, referindose, nesse caso, ao peso excessivo das formas de Estado do Bem-Estar Social instituídas nesses países.

A discussão sobre a participação social no contexto brasileiro tem, assim, alcançado centralidade nos últimos 20 anos, não apenas nos meios políticos, mas também acadêmicos. Ainda que muitos autores apresentem e discutam a participação como forma de ampliação dos direitos dos cidadãos e de fortalecimento da democracia (COUTO, 2004; JELIN E HERSHBERG, 2006; NOGUEIRA, 2004; HAGUETTE, 1994; JACOBI, 2002; PUTNAM; 2000, entre outros), há os que consideram, também, a abertura desse novo espaço de participação direta na gestão pública - discutindo o procedimento emblemático de participação, que é o orçamento participativo - como um processo que concede legitimidade ao executivo para prescindir do legislativo, aprofundando as tensões já existentes entre os dois poderes (FADUL e MUNIZ, 2000). Ainda que nos últimos anos se assista a uma crise da democracia representativa em diversos países, esses autores destacam que, em uma democracia nos padrões contemporâneos, o poder legislativo ainda é o locus no qual a vontade popular deve ser legitimamente forjada e defendida.

Nesse sentido, é possível vislumbrar, nos processos participativos atuais, tanto naqueles que tratam da formulação de políticas públicas, quanto nos que atuam diretamente na gestão pública, uma nova forma de exercício do poder do povo através da cooperação, verificando se há, assim, a possibilidade de se alcançar um novo modelo regulatório das relações entre Estado, mercado e sociedade, conforme sugerem Kissler e Heidemann (2006) quando tratam da governança pública na Alemanha.

$\mathrm{Na}$ gestão dos recursos hídricos no Brasil, objeto empírico deste estudo, ocorreram mudanças profundas quando o governo brasileiro adotou um modelo de gestão baseado nos pilares da integração, descentralização e participação. Analisando esse modelo como desenho organizacional para a gestão de um bem público puro, é possível afirmar que essas estruturas constituem uma inovação no cenário político e institucional brasileiro, tanto no que se refere à sua arquitetura organizacional, quanto aos seus procedimentos de funcionamento. No entanto, salvo algumas exceções, pesquisas têm mostrado as fragilidades, dificuldades e a incipiência da maior parte desses comitês, sobretudo aqueles localizados na região nordeste (HAASE, 2005; SANTOS E SAITO, 2006; MORAES, 2012; BERRETA, 2013, FADUL et al, 2011; FADUL et al, 2013; MORAIS e FADUL, 2013; FADUL e NUNES, 2014).

Essas estruturas são órgãos colegiados criados em formato descentralizado, não estando subordinados nem à instância federal, nem às estaduais, porém altamente dependentes dos Poderes Executivos de ambas as esferas, federal e estadual, por força dos mecanismos de integração da gestão estabelecidos pela mesma lei. É o que este artigo discute, focando no setor de recursos hídricos e utilizando como objeto de estudo os comitês de bacias hidrográficas institucionalizados pela legislação federal em 1997.

O foco deste trabalho é avaliar criticamente os mecanismos do processo participativo no âmbito desses organismos, já que são organizações formais criadas no bojo da efervescência da descentralização e dos processos participativos da sociedade na condução da coisa pública. Debruçando-se sobre o setor de recursos hídricos, busca-se estender os debates sobre a participação em direção à análise da efetivação de tal princípio na tomada de decisão acerca do uso e do gerenciamento das águas no país, utilizando como objeto de estudo os comitês de bacias hidrográficas do Estado da Bahia institucionalizados pela chamada Lei das Águas de 1997.

O trabalho tem por objetivo fazer uma discussão dessa temática por entender que a consolidação de mecanismos e de espaços de debates públicos com o envolvimento do cidadão fortalece a democracia, visa dar maior eficiência às políticas públicas e aproximar Estado e sociedade. Na gestão dos recursos hídricos o arcabouço legal é válido, moderno e avançado ao estabelecer os comitês de bacias como espaços para dirimir conflitos, preservar a bacia hidrográfica e gerenciar os recursos que serão arrecadados com a instituição da cobrança do uso da água. Contudo, não só os mecanismos de participação devem ser assegurados pela Lei, mas deve ser observada, também, a sua efetiva aplicação.

Além desta introdução, o artigo traz algumas notas acerca dos processos participativos de modo geral e especificamente na gestão das águas no país. Em seguida, caracteriza de que forma ocorre o processo de participação e o controle social no interior desses comitês, identificando tipos e formas de participação. Apresenta a metodologia do estudo, para, por fim, discutir em que resulta esse processo participativo de gestão das águas instituído no país há quase 20 anos e apresentar as conclusões.

\section{PARTICIPAÇÃO SOCIAL}

A democracia, regime que tem se disseminado no mundo ao longo dos anos, traz consigo as bases e as condições para permitir que as pessoas tenham o direito de participar das decisões do Estado, não 
apenas pela via do voto direto. Bordenave (1994, p. 8) afirma: "Democracia é um estado de participação".

Segundo Habermas (1997), a teoria pluralista compreende a ideia de que o poder político e o administrativo são formas diferentes de manifestação do poder social. Nessa visão, o poder social pode se manifestar por meio da imposição de interesses organizados através das eleições e da disputa entre partidos, transformando-se em poder político entre os representantes eleitos, seja tanto do governo, quanto da oposição.

Para o autor, esse modelo é cíclico, em que o poder social dos clientes está ligado aos partidos, que, por conseguinte, atingem o poder político passando pelo poder administrativo através das ações do Estado, em que se articulam essas ações estatais com os interesses dos clientes.

A ideia de uma democracia de concorrência, em que as organizações e associações substituem o papel dos cidadãos, traria uma ideia de equilíbrio do poder social em relação ao acesso ao poder político, permitiria que as ações do Estado ocorressem considerando múltiplos interesses (HABERMAS, 1997). Contudo, pondera o autor, a seletividade de determinados grupos viola o pluralismo e conduz a luta do poder apenas pelas elites e com isso conduz ao atendimento de interesses apenas desse grupo.

A ideia de que essas elites atuaram com a implementação de ações pelo Estado que atendam a diversos interesses é utópico e ingênuo. Outros espaços e mecanismos de contestação devem emergir para que os interesses diversos sejam atendidos pelas ações do Estado.

A esfera pública em Habermas é um caminho. Conceitualmente, o autor pondera que esfera pública não é um sistema ou uma organização com uma estrutura normativa definida, com definições claras de competências e/ou papéis. Para Habermas (1997), esfera pública é um fenômeno social, em rede, capaz de comunicar conteúdos, tomar posições e opiniões, capaz de reconhecer, contextualizar, e dramatizar os problemas de forma convincente, ao ponto de exercer pressão nas organizações representativas e no poder político, para que possam ser assumidos e soluções exprimidas através das ações do Estado.

Para Habermas (1997 p. 92):

A esfera pública constitui principalmente uma estrutura comunicacional do agir orientado pelo entendimento, a qual tem a ver com o espaço social gerado no agir comunicativo, não com as funções nem com os conteúdos da comunicação cotidiana.

E, nesse ponto, um elemento também essencial nesse processo é a sociedade civil. Bresser-Pereira (1995) ainda define sociedade civil como aquela "organizada pelo mercado" (p. 33), ou sendo o próprio mercado. Porém, o autor faz a ressalva de que a sociedade civil incorpora a vida familiar, regulada pelo Estado, e a vida produtiva e econômica, regulada pelo mercado e pelo Estado. Para Habermas (1997), a sociedade civil é composta por movimentos, organizações e associações que captam os problemas sociais nas esferas privadas e dão ressonância na esfera pública.

A participação da sociedade civil exige politização e, quando os seus espaços onde o seu poder é inerente são substituídos ou deixam de ser utilizados para o debate, o princípio democratizante se esvai e deixa espaço para posições estritamente individuais (TEIXEIRA, 2001). Além disso, a ocorrência e incidência de assimetrias no exercício da participação, bem como a limitação cognitiva e de recursos, podem atrapalhar uma ação mais efusiva da sociedade civil (TEIXEIRA, 1999). Teixeira (1999) ressalta ainda que papel da sociedade civil, cujo caráter institucional é embasado em direitos sociais, confronta o sistema não só para manter esses direitos, mas para conquistar novos.

Contudo, a socialização da participação política proposta por Coutinho (2005) esbarra em fatos intrínsecos ao poder do Estado e que impedem uma maior participação popular: o fato de o Estado ser governado por um grupo de pessoas, mesmo que representantes eleitos, cuja socialização do poder não seria uma alternativa para seus projetos de alienação, conforme a ponderação feita por Habermas sobre as elites dominarem o poder político em detrimento dos demais interesses da maioria.

No caso do Brasil, é possível perceber que seria um indício da "herança centralizadora" do Estado, que visa limitar ou anular a participação popular em questões estratégicas. Antes do processo que marcou, ou melhor dizendo, assegurou legalmente a participação da sociedade civil em decisões do Estado, cabe observar que a luta e resistência ao regime autoritário que seguia no Brasil na década de 70 , que, na sua gênese e essência, vedava a participação social. Essa luta pode ser considerada como o marco da sociedade civil organizada no Brasil (AVRITZER, 1994).

Essa luta reuniu vários setores organizados, ou não, como sindicatos, imprensa, igrejas, universidades, jornalistas e advogados, dentre outros, que contribuíram decisivamente para o retorno de garantias caras a um modelo democrático, como eleições diretas, organização de partidos políticos e liberdade de imprensa, por exemplo (DAGNINO, 2002). A autora reforça que a luta pela democratização unificou a sociedade civil, mesmo que, depois, por conta de projetos políticos distintos, ela se revelasse heterogênea. Contudo, ao longo do tempo, verificou-se a incapacidade do Estado em resolver os problemas sociais e desigualdade no país, exigindo dessa mesma sociedade maior participação e controle social do Estado (DAGNINO, 2002). 
Reivindicações que encontraram salvaguarda na Constituição Federal de 1988, considerada como um marco para o processo de formulação e acompanhamento das políticas públicas através da participação e do controle social, exercidos pela sociedade civil organizada no Brasil. Evidenciam-se formas de manifestação social tais como o movimento popular urbano, reivindicatório e de massa; as experiências coletivas com a proposição de políticas públicas e na integração de conselhos; bem como as iniciativas de controle dos recursos públicos e elaboração de orçamentos públicos (AUGUSTO FRANCO, 1994).

$\mathrm{Na}$ visão de Caetano, Souza e Enders (2006), na Constituição Federal de 1988 foi posto, pela primeira vez na agenda brasileira, o debate nacional acerca da possibilidade do controle, pela sociedade civil, da aplicação dos recursos por intermédio das políticas públicas. Reforçando essa prerrogativa constitucional, sob o ponto de vista da modernidade e contemporaneidade, Silva e Luiz (2012) apregoam no contexto atual uma gama de possibilidades e limites na relação entre Estado e sociedade e que tutelam os contornos da esfera democrática. Esse fenômeno foi ocorrendo, no entendimento de Teixeira (1997), em função da crise do Estado e da sua incapacidade de atender e dar respostas aos anseios da sociedade, sobretudo aos mais necessitados, ou, na visão de Arnstein (2002), aos sem nada, reforçando o surgimento de movimentos sociais e populares que passam a exigir participação dos cidadãos em decisões do Estado.

$\mathrm{Na}$ visão de Arnstein (2002), participação social corresponde, então, ao cidadão no poder, entendendo que o cidadão ao qual se refere são os indivíduos que a autora chama de sem nada, ou seja, grupos excluídos pela sociedade, como negros, índios e outros que não têm espaço ou direito em participar das decisões de Estado. Com essa perspectiva, Arnstein (1969) propôs um modelo de classificação, o qual chamou de escada da participação cidadã, apresentada no Quadro 01, a seguir, comportando oito degraus. Cada degrau representa a medida de poder que os cidadãos têm de influenciar no resultado final do processo de planejamento. Para a autora, essa escala não consiste apenas em uma nomenclatura, mas representa as condições que caracterizam um crescente grau de participação real do cidadão no processo decisório e de planejamento.

Assim, o nível de participação do cidadão aumenta na medida em o mesmo alcança o degrau superior na escada. Para a autora, não existe participação nos dois primeiros degraus, quais sejam, manipulação e terapia, sendo os mesmos considerados "níveis de não-participação". Os três níveis seguintes (informação, consulta e pacificação) apresentam uma "política do menor esforço", sendo, por isso, considerados como "níveis de concessão mínima de poder". A partir do sexto degrau (parceria), o cidadão começa ser capaz de influenciar efetivamente nos resultados, passado, assim, para os "níveis de poder cidadão" (ARNSTEIN, 1969, p. 2).

\begin{tabular}{|c|c|c|}
\hline Escala & Conceito & Nível de Particinacão \\
\hline $\begin{array}{l}\text { 8. Controle } \\
\text { pelo cidadão }\end{array}$ & $\begin{array}{l}\text { Cidadãos responsáveis pelo planejamento, pela política, assumindo a gestão } \\
\text { em sua totalidade, sem intermediários. }\end{array}$ & Níveis de Poder Cidadão \\
\hline $\begin{array}{l}\text { 7. Delegação } \\
\text { de poder }\end{array}$ & $\begin{array}{l}\text { Cidadãos ocupando a maioria dos assentos nos comitês, com poder delegado } \\
\text { para tomar decisões. Nesse caso, o público tem poder para assegurar as contas } \\
\text { do programa para si. }\end{array}$ & Níveis de Poder Cidadão \\
\hline 6. Parceria & $\begin{array}{l}\text { Poder distribuído por uma negociação entre cidadãos e detentores do poder. O } \\
\text { planejamento e as decisões são divididos pelos comitês. }\end{array}$ & Níveis de Poder Cidadão \\
\hline 5. Pacificação & $\begin{array}{l}\text { O cidadão começa a ter certo grau de influência nas decisões, podendo } \\
\text { participar dos processos de tomada de decisão, entretanto, não existe a } \\
\text { obrigação dos tomadores de decisão de levar em conta o que ouviram. }\end{array}$ & $\begin{array}{l}\text { Níveis de Concessão } \\
\text { mínima de poder }\end{array}$ \\
\hline 4. Consulta & $\begin{array}{l}\text { Caracterizado por pesquisas de participação, reuniões de vizinhança etc. } \\
\text { Segundo os autores, serve somente como fachada, não possui muita implicação } \\
\text { prática. }\end{array}$ & $\begin{array}{l}\text { Níveis de Concessão } \\
\text { mínima de poder }\end{array}$ \\
\hline 3. Informação & $\begin{array}{l}\text { Informar as pessoas sobre seus direitos, responsabilidades e opções. } \\
\text { Entretanto, trata-se de um fluxo de informação somente de cima para baixo. }\end{array}$ & $\begin{array}{l}\text { Níveis de Concessão } \\
\text { mínima de poder }\end{array}$ \\
\hline 2. Terapia & $\begin{array}{l}\text { Os técnicos de órgãos públicos se escondem atrás de conselhos e comitês } \\
\text { participativos para não assumir erros cometidos por eles e diluir a } \\
\text { responsabilidade. }\end{array}$ & Não-participação \\
\hline 1. Manipulação & $\begin{array}{l}\text { Tem como objetivo permitir que os atores sociais que conduzem o processo } \\
\text { possam educar as pessoas. Manifesta-se em conselhos onde os conselheiros } \\
\text { não dispõem de informações, conhecimento e assessoria técnica independente, } \\
\text { necessários para tomar decisões por conta própria. }\end{array}$ & Não-participação \\
\hline
\end{tabular}

\section{PARTICIPAÇÃO SOCIAL NA GESTÃO DOS RECURSOS HÍDRICOS}

O contexto internacional e ambiental também impõe uma pressão tanto quanto à necessidade da descentralização, participação e regulação, quanto à cobrança feita pelo uso da água. $O$ debate quanto à disposição de mecanismos capazes de promover a democratização do acesso e diminuir a possibilidade da escassez da água torna o tema iminente e emergencial, visto que os recursos financeiros arrecadados a partir de um modelo de gerenciamento participativo e descentralizado poderiam ser utilizados em beneficio 
do próprio sistema.

Essas proposições foram defendidas em algumas conferências nacionais e internacionais tais como a Agenda 21, a Conferência de Dublin de 1992 e a Assembleia Geral da Rede Internacional de Organismos de Bacia (RIOB), em 1998, a qual, dentre outras proposições, definiu e defendeu formulações importantes para o setor, quais sejam:

- o iminente processo de escassez da água, do ponto de vista de condições de consumo;

- a necessidade crescente de atribuir um valor de mercado a esse bem, em função dessa escassez e da importância desse recurso;

- o entendimento de que as políticas públicas e soluções acerca dessa questão devem ter caráter de longo prazo e não ser apenas pontuais e localmente circunscritas;

- a defesa pela implementação de um gestão global dos recursos hídricos a fim de promover a proteção dos recursos naturais e a satisfação das necessidades dos diversos usuários;

- a defesa pela diminuição da poluição de qualquer grau e espécie e promoção da proteção e a restauração dos ecossistemas e espaços aquáticos;

- a defesa da participação na tomada de decisão pelos agentes territoriais juntos as entidades governamentais a fim de garantir as necessidades de todas as categorias de usuários e a implementação de um programa de financiamento apropriado (SANTOS, 2002. p. 03).

Corroborando ainda com a proposição da participação social nesse processo, Marco (1998), cultua o usuário como protagonista do processo decisório de gestão das águas. No contexto internacional, ainda é possível citar a Conferência Internacional sobre as Águas ocorridas em março de 2000, em Haia, na Holanda, na qual alguns representantes de diversos países defenderam a necessidade da descentralização, da participação e da instituição da cobrança pelo uso da água, como sendo uma das formas mais eficazes de equacionamento da questão da escassez (SANTOS, 2002).

Ainda nessa conferência, discutiu-se a necessidade de findar o monopólio estatal que prevalecia na maioria dos países e procurar redefinir as formas de relações entre o setor público e privado (SANTOS, 2002). Há que se considerar que o contexto era favorável a esse tipo de proposição, tendo em vista a efervescência dos princípios da política neoliberal amplamente propagada no mundo ocidental, que estimulava a participação da iniciativa privada como prestador dos serviços e o Estado assumindo o papel de regulador. De acordo com Bezerra e Silva (2005) do ponto de vista da participação e controle social, a política das águas no Brasil instituiu instrumentos e processos de decisão participativa que a conceitua com uma das mais avançadas na gestão descentralizada no mundo.

A experiência brasileira com os comitês de bacias pode ser considerada ainda recente e começou com a implementação do Comitê do rio São Francisco, que contou com o suporte da Agência Nacional de Águas - ANA (FADUL et al. 2011) o que reforça a ideia da necessidade de haver um apoio institucional a fim de garantir o amadurecimento da implementação de um comitê de bacia. Essa experiência permite colher resultados quanto à cobrança pelo uso da água, mas quanto aos processos de descentralização e a participação não pode ser considerada efetiva, visto que o projeto de transposição do Rio São Francisco foi conduzido no âmbito da esfera federal, sem a participação do comitê. Há, também, as experiências paulistas e de outras localidades no sul e sudeste que podem ser destacadas como experiências de sucesso na adoção desse modelo de gestão e na instituição da cobrança pelo uso da água. Cabe indagar que fatores favoreceram esse êxito.

Nesse questionamento quanto à efetividade da política de recursos hídricos a partir dos conceitos de descentralização, participação e controle social é necessário discutir, também, de que forma essa autonomia ou participação ocorre de maneira, considerando que a administração pública brasileira acaba centralizando as políticas de recursos hídricos de cada região. O questionamento encontra respaldo na observação de Santos (2002) de que descentralização e a participação não estão imbricadas. Ou seja, nem toda a descentralização leva a um maior grau de participação.

Há de se considerar inclusive a relação inversamente proporcional entre necessidade e possibilidade reais de participação, as possibilidades de assimetria e a fragmentação do tecido social (GRAU, 1996 apud SANTOS, 2002). Assim, a implementação de um modelo de gestão descentralizado, por bacia hidrográfica, pode se constituir em um avanço, mas pode também resultar tão somente na instrumentalização das relações entre Estado e sociedade civil, na extensão das relações mercantis no âmbito da sociedade, ou seja, na radicalização de processos que tem como marca fundamental a instrumentalização e a mercantilização das relações entre sociedade e natureza [...] (SANTOS, 2002, p. 11).

Ainda para a autora a descentralização pode ter um resultado avesso. Pode se constituir em práticas de clientelismo, ineficiência e inoperância, e pode contribuir para a despolitização o movimento social. Considera-se, ainda, que a descentralização pode ser uma determinação do Estado, que se envolveria na escolha dos sujeitos, privilegiando cliente e usuários, já que a participação envolve consciência política, 
organização e amadurecimento.

Abers e Jorge (2005) corroboram com Santos (2002) ao discorrerem que na gestão dos recursos hídricos a descentralização e a participação se alicerçam em três fundamentos principais: em primeiro lugar, esse processo de descentralização deve ocorrer nos níveis nacional e estadual, com a criação de organismos de bacias nas duas esferas, ou seja, tanto para águas federais quanto para águas estaduais; segundo, que a descentralização não deveria ocorrer com a transferência de poder para instâncias mais locais como os municípios, mas a partir da criação de uma nova esfera territorial, no caso a bacia hidrográfica e, por fim, o terceiro aspecto a ser levado em conta é o caráter semivoluntário dessa descentralização, que obriga os comitês a serem criados para todas as bacias.

$\mathrm{Na}$ visão de Teixeira (2001) a efetiva participação depende de mecanismos existentes; institucionais ou não. Sendo eles institucionais há risco da participação ser às avessas, pois poderá está submetida à lógica do poder dominante ou da racionalidade técnico-burocrática. Nesse sentido, emerge como fundamental a existência de uma sociedade civil organizada e com autonomia com relação ao Estado e ao mercado, para que a participação seja efetiva, o que requer a necessidade da constituição de espaços públicos livres para que os organismos sociais possam se organizar em busca de informações, formação de opinião e na capacidade de se mobilizar para questionar as decisões políticas do estado (TEIXEIRA, 2001).

$\mathrm{Na}$ visão desse autor, um dos ditames da participação é o papel na decisão. Cita Dahl (1992) e Habermas (1992) para caracterizar o processo decisório e a participação cidadã em cinco pontos chaves: a) inclusão de todos os afetados, b) igual distribuição de oportunidades de participar no processo político; c) igual direito a votar nas decisões; d) igual direito de escolher tópicos e controlar a agenda e, e) situação que permita a todos os participantes desenvolverem uma articulada compreensão dos assuntos necessários a regulação de interesses contestados.

Conforme se observa no Quadro 02, a seguir, apenas a inclusão dos afetados, por compartilhar o poder sobre a política e o igual direito de votar no comitê de Bacia podem ser destacados na Lei das Águas.

QUADRO 02 - Participação social na lei das águas

\begin{tabular}{|c|c|c|}
\hline Mecanismos na Lei & Poder Público & Compartilhado \\
\hline $\begin{array}{l}\text { I os Planos de } \\
\text { Recursos Hídricos; }\end{array}$ & & $\begin{array}{l}\text { Conforme a Lei das Águas em seu artigo. 80 Os Planos de } \\
\text { Recursos Hídricos serão elaborados por bacia hidrográfica, } \\
\text { por Estado e para o País. Nesse caso, os comitês de Bacias } \\
\text { são os responsáveis pela elaboração desses planos de } \\
\text { Recursos Hídricos. A maioria desses comitês não possui } \\
\text { recursos para a elaboração desses planos, o que requereria } \\
\text { recursos do estado para elaboração. Pode-se observar que a } \\
\text { depender de quais interesses o Estado seja subserviente, os } \\
\text { recursos podem não serem destinados e os planos não } \\
\text { serem elaborados e impedirem a implementação da cobrança } \\
\text { do uso da água conforme rege a Lei das águas. }\end{array}$ \\
\hline $\begin{array}{l}\text { II - o enquadramento } \\
\text { dos corpos de água em } \\
\text { classes, segundo os } \\
\text { usos preponderantes da } \\
\text { água; }\end{array}$ & $\begin{array}{l}\text { Esse enquadramento é feito poder público } \\
\text { mediante a definição da Lei Ambiental. } \\
\text { Art. 10. As classes de corpos de água serão } \\
\text { estabelecidas pela legislação ambiental. }\end{array}$ & \\
\hline $\begin{array}{l}\text { III - a outorga dos } \\
\text { direitos de uso de } \\
\text { recursos hídricos; }\end{array}$ & $\begin{array}{l}\text { Esse poder é concedido ao Estado que é } \\
\text { responsável pela implementação da Política } \\
\text { Estadual dos Recursos Hídricos. No caso } \\
\text { da Bahia, essa responsabilidade é do } \\
\text { INEMA. } \\
\text { Art. 14. A outorga efetivar-se-á por ato da } \\
\text { autoridade competente do Poder Executivo } \\
\text { Federal, dos Estados ou do Distrito Federal. } \\
\text { No artigo } 29 \text {, inciso II, dessa mesma lei, } \\
\text { ratifica esse poder e ainda indica como de } \\
\text { sua competência a fiscalização: II - } \\
\text { outorgar os direitos de uso de recursos } \\
\text { hídricos, e regulamentar e fiscalizar os } \\
\text { usos, na sua esfera de competência; }\end{array}$ & $\begin{array}{l}\text { A outorga pode ser feita mediante a indicação do Comitê de } \\
\text { Bacia, desde que classificada como captações e lançamentos } \\
\text { de pouca expressão, conforme previsto no inciso V do artigo } \\
\text { que versa sobre as competências dos comitês de Bacias. } \\
V \text { - propor ao Conselho Nacional e aos Conselhos Estaduais } \\
\text { de Recursos Hídricos as acumulações, derivações, captações } \\
\text { e lançamentos de pouca expressão, para efeito de isenção da } \\
\text { obrigatoriedade de outorga de direitos de uso de recursos } \\
\text { hídricos, de acordo com os domínios destes. } \\
\text { Além disso, a outorga deve estar condicionada as prioridades } \\
\text { de uso e à classificação do corpo de água, bem como aos } \\
\text { critérios de usos múltiplos. } \\
\text { Art. 13. Toda outorga estará condicionada às prioridades de } \\
\text { uso estabelecidas nos Planos de Recursos Hídricos } \\
\text { Cabendo ao comitê a aprovação de tal plano, conforme inciso } \\
\text { III do artigo 37: } \\
\text { Art. } 37 \text {. Os Comitês de Bacia Hidrográfica terão como área de } \\
\text { atuação: III - aprovar o Plano de Recursos Hídricos da bacia; }\end{array}$ \\
\hline $\begin{array}{l}\text { IV - a cobrança pelo } \\
\text { uso de recursos } \\
\text { hídricos; }\end{array}$ & & $\begin{array}{l}\text { Caberá ao comitê de bacias Hidrográficas a instituição dos } \\
\text { mecanismos de cobrança pelo uso da água. Esse comitê é } \\
\text { composto por representes do poder público, da sociedade } \\
\text { civil e dos usuários da água. A gestão dos recursos } \\
\text { provenientes da instituição da cobrança pelo uso da água é } \\
\text { feita na Agência das águas, que estará subordinada ao } \\
\text { comitê. }\end{array}$ \\
\hline
\end{tabular}




\begin{tabular}{|c|c|c|}
\hline $\begin{array}{l}\text { VI - o Sistema de } \\
\text { Informações sobre } \\
\text { Recursos Hídricos. }\end{array}$ & $\begin{array}{l}\text { Cabe ao poder Público: } \\
\text { III - implantar e gerir o Sistema de } \\
\text { Informações sobre Recursos Hídricos, em } \\
\text { âmbito estadual e do Distrito Federal. } \\
\text { Mesmo sendo um mecanismo } \\
\text { implementado pelo Poder Público o objetivo } \\
\text { desse Sistema é fornecer informações e } \\
\text { subsidiar a elaboração dos planos dos } \\
\text { recursos hídricos. Fornecer informações a } \\
\text { todos integrantes do sistema é uma } \\
\text { característica de acesso à informação e não } \\
\text { descentralizadora conforme previsto na Lei. }\end{array}$ & \\
\hline $\begin{array}{l}\text { Conselho Nacional dos } \\
\text { Recursos Hídricos }\end{array}$ & & $\begin{array}{l}\text { É composto por representantes do poder público, usuários e } \\
\text { representantes da sociedade civil. Tem como competência, } \\
\text { dentre outras, arbitrar sobre os conflitos do uso das águas em } \\
\text { última instância. }\end{array}$ \\
\hline $\begin{array}{l}\text { Comitê de } \quad \text { Bacias } \\
\text { Hidrográficas }\end{array}$ & & $\begin{array}{l}\text { É composto por representantes do poder público, usuários e } \\
\text { representantes da sociedade civil. Tem como competência } \\
\text { arbitrar sobre os conflitos do uso das águas em primeira } \\
\text { instância, outorga do uso da água de pouca expressão, } \\
\text { acompanhar a cobrança e gestão dos recursos provenientes } \\
\text { através da Agência das Águas. }\end{array}$ \\
\hline
\end{tabular}

FONTE: elaboração própria com base na Lei nำ9433/97.

\section{METODOLOGIA}

O trabalho consiste em um estudo exploratório e descritivo de cunho teórico-empírico visto que faz uma análise dos mecanismos de participação social dispostos na Lei das Águas e uma análise da sua efetividade na gestão dos comitês de bacias do Estado da Bahia, a partir da análise das atas de reunião dos comitês.

É uma pesquisa de abordagem qualitativa. Na concepção de Minayo (2001), a pesquisa qualitativa visa aprofundar as relações e as causas de fenômenos e que evidentemente não tem direta relação com as variáveis. Goodoy (1995, p. 21) complementa afirmando que, nesse tipo de pesquisa, um "fenômeno pode ser compreendido no contexto em que ocorre e do qual é parte".

Especificamente a pesquisa qualitativa neste trabalho visa estabelecer as possibilidades, entraves e dificuldades no processo de participação social nos comitês de bacia hidrográfica, através da análise dos instrumentos de gestão definidos na Lei das águas.

Atualmente, o estado da Bahia possui 14 comitês de bacias hidrográficas: $\mathrm{CBH}$ Contas, $\mathrm{CBH}$ Corrente, CBH Frades, Buranhém e Santo Antônio, CBH Grande, CBH Itapicuru, CBH Leste, CBH Paraguaçu, $\mathrm{CBH}$ Paramirim e Santo Onofre, CBH Peuípe, Itanhém e Jucururu, Recôncavo Norte e Inhambupe, CBH Recôncavo Sul, CBH Salitre, CBH Sobradinho e CBH Verde-Jacaré (INEMA, 2013).

As atas de reuniões que foram analisadas nesse estudo constam no site do INEMA - Instituto de Meio Ambiente e Recursos Hídricos, disponibilizadas em um espaço específico para cada comitê. O horizonte temporal de análise compreende o período entre 2006 (ano de criação do primeiro comitê de bacia no estado da Bahia) a 2014.

O estudo foi dividido em três etapas distintas. Primeiramente, foram revisitados os pressupostos teóricos da participação e controle social, bem como as metodologias que buscam verificar níveis de participação social. $\mathrm{Na}$ segunda etapa do trabalho foram analisados os mecanismos de participação dispostos na Lei das Águas e, por último, como terceira etapa apresentam-se as conclusões acerca da efetividade da participação social na gestão dos recursos hídricos.

\section{ANÁLISE DOS RESULTADOS}

A gestão das águas no Brasil mudou sensivelmente a partir da promulgação da Lei no 9.433/97, a Lei das Águas. Tal lei promoveu um conjunto considerável de mudanças no setor por meio da descentralização das decisões de gestão ao estabelecer a bacia hidrográfica como base de implementação da Política Nacional de Recursos Hídricos, através da instituição dos comitês de bacia hidrográfica. Dessa forma, a lei estabelece também uma série de instrumentos novos para a gestão do setor, apoiados em diretrizes inovadoras, que buscam integrar a gestão das águas, do solo e ambiental.

Tendo o modelo brasileiro sido inspirado na experiência francesa de gestão de recursos hídricos e de saneamento, tem como base a participação dos usuários de água e, como um dos instrumentos, a cobrança pelo uso do recurso, delegando aos comitês a responsabilidade pela arrecadação e pela destinação dos recursos. Dessa forma, o atual modelo de gestão dos recursos hídricos está baseado nos pilares da integração, descentralização e participação - sendo a integração percebida verticalmente pela necessidade de articulação entre as esferas federal, estadual e municipal e horizontalmente pela articulação da gestão 
dos recursos hídricos com a gestão do solo e do meio-ambiente, expressamente determinada pela Lei das Águas, bem como na articulação dos diversos setores da sociedade; a descentralização percebida pela determinação dos comitês de bacia, que atuam localmente, como unidades básicas de gestão; e a participação verificada pela composição dos comitês, obrigatoriamente contendo membros representantes do governo, dos usuários e da sociedade.

A implementação do Sistema Nacional de Gerenciamento de Recursos Hídricos - SINGREH, fruto da inovação institucional proposta por esta Lei, ocorreu por conta do ajustamento às demandas por participação e descentralização da sociedade. Tal descentralização se revela por meio da criação de organismos de tomada de decisão ao nível nacional, estadual e de bacia (conselhos e comitês). Esses organismos passaram a incorporar representantes de novos atores (municípios, usuários e organizações civis) ao processo de gestão. Ocorre a descentralização em razão da transferência da responsabilidade de execução das decisões das estruturas centrais para as locais, no caso bacia hidrográfica (BERRETA, 2013).

Dessa forma, como assevera Berreta (2013), tendo os comitês sido idealizados como um fórum de decisões políticas, os mesmos se constituem como "parlamentos das águas da bacia". Pois são constituídos legalmente e, por tanto, obrigatoriamente, pelos os representantes dos usuários das águas, do poder público (União, Estado e Municípios, dependendo do domínio da bacia) e da sociedade civil organizada, além dos demais níveis de governo, num processo de negociação no âmbito da bacia hidrográfica. Vale ressaltar que a participação nos comitês pelo cidadão, só acontece por meio de representação de entidades civis, não sendo possível a participação individual.

O Quadro 03 mostra o nível de participação dos diversos membros dos comitês no estado da Bahia, considerando a participação dos mesmos nas deliberações desses órgãos. Tal índice está baseado nas interferências realizadas durante a discussão e votação das pautas apresentadas.

\begin{tabular}{|c|c|c|c|c|c|c|c|c|c|}
\hline \multicolumn{10}{|c|}{ QUADRO 03 - NÍVEL DE PARTICIPAÇÃO DOS INTEGRANTES DOS CBH } \\
\hline Membro & \multicolumn{3}{|c|}{ Poder Público } & \multicolumn{3}{|c|}{\begin{tabular}{|c||} 
Usuários \\
\end{tabular}} & \multicolumn{3}{|c|}{ Sociedade Ciril } \\
\hline Comitê & Percentual & Assiduidade & Participação & Percentual & Assiduidade & Participação & Percentual & Assiduidade & Participação \\
\hline $\mathrm{CBH}$ Contas & 58 & 87 & 100 & 11 & 68 & 83 & 32 & 74 & $4 \quad 64$ \\
\hline CBH Corrente & 54 & 93 & 100 & 23 & 62 & 87] & 23 & 85 & 75 \\
\hline CBH Frades, Buranhém e Santo & & & & & & & & & \\
\hline Antônio & 38 & 95 & 100 & 29 & 66 & 88 & 33 & 83 & 73 \\
\hline CBH Grande & 47 & 83 & 100 & 27 & 64 & 79 & 26 & 79 & 69 \\
\hline CBH Itapicuru & 52 & 87 & 100 & 17 & 72 & 86 & 31 & 81 & 71 \\
\hline CBH Leste & 53 & 84 & 100 & 17 & 65 & 79 & 30 & 78 & 68 \\
\hline CBH Paraguaçu & 47 & 95 & 100 & 21 & 73 & 79 & 32 & 91 & 91 \\
\hline CBH Paramirim e Santo Onofre & 39 & 93 & 100 & 29 & 72 & 76 & 32 & 84 & 74 \\
\hline CBH Penuipe, Itanhém e & & & & & & & & & \\
\hline Jucuruçu & 53 & 94 & 100 & 10 & 69 & 76 & 37 & 90 & 70 \\
\hline CBH Recôncavo Norte e & & & & & & & & & \\
\hline Inhambupe & 48 & 98 & 100 & 25 & 78 & 100 & 27 & 97 & 100 \\
\hline CBH Recôncavo Sul & 54 & 98 & 100 & 23 & 75 & 76 & 23 & 89 & 79 \\
\hline CBH Salitite & 49 & 84 & 100 & 12 & 65 & 77 & 39 & 85 & 75 \\
\hline CBH Sobradinho & 58 & 98 & 100 & 17 & 78 & 100 & 25 & 96 & 100 \\
\hline CBH Verde-Jacaré & 52 & 83 & 100 & 14 & 62 & 79 & 34 & 74 & 64 \\
\hline
\end{tabular}

FONTE: Elaboração própria com base nas atas disponíveis no site do INEMA (2014).

Existem diversos problemas no processo de participação e representação, bem como na própria formação dos comitês: a) Falta de recursos dos representantes da sociedade para o deslocamento até os locais das reuniões; b) Predominância do grupo de áreas onde se encontram a maior concentração dos usuários; c) Baixa participação de todos os segmentos, principalmente da sociedade civil, por causa da pouca divulgação; d) Vários municípios não participam; e) Falta do entendimento do que é o comitê de bacia hidrográfica, por parte da população; g) Falta de interesse; h) Mobilização ineficiente.

Dois fatores contribuem diretamente como o baixo nível de participação da sociedade civil em alguns dos comitês: primeiro, o distanciamento entre os locais de conflito, em torno dos usos dos recursos hídricos, e alguns representantes com assento no comitê, que buscavam soluções, sem conhecimento da realidade local. O segundo é a contratação dos mobilizadores regionais sem o perfil adequado para atuarem com os 
atores sociais, o que possibilita perceber que a escolha desses é feita através de indicações, sem muitos critérios.

A participação nos comitês tem o objetivo primário de neutralizar e inibir tomadas de decisão apoiadas em lógicas individualistas ou estritamente economicistas. A intenção do modelo é garantir uma interação mais clara e transparente entre as três esferas de interesse envolvidas, por meio da diversidade de suas origens e interesses. A finalidade, assim é limitar a ocorrência de abuso do poder legal ou econômico nas decisões. Isso, entretanto não diminui ou impede o risco de captura associados ao modelo. Assim, fica evidente que tais mudanças propostas pela Lei das Águas tornam a gestão dos recursos hídricos um processo bastante politizado, reforçando a ideia de um modelo no qual a política ambiental é abrangente, envolvendo a sociedade civil por meio de um processo de consulta e envolvimento na tomada de decisão na gestão das águas (SOUZA JÚNIOR, 2004).

Para Santos e Saito (2013, p. 7), esse modelo gestão dos recursos hídricos gerou o surgimento de um mito da participação social: "Em meio à ampla divulgação e exaltação da defesa do princípio participativo da atual Política Nacional de Recursos Hídricos, cabe destacar que a discussão sobre participação aparece de forma mitificada". Dessa forma os autores apontam três aspectos que fundamentam tal ideia.

O primeiro aspecto se refere à origem da participação. Isso porque, para a sociedade brasileira a participação social tem sido encarada, ou mesmo apresentada, sob dois prismas distintos. Em alguns momentos como uma dádiva, ou quase um favor do Estado, em outros, como uma estratégia para minimizar os conflitos originados da gestão de uma determinada política pública. Em ambos os casos a fonte aparente da participação é o poder público ou os setores dominantes da sociedade, sendo vista como uma espécie de concessão daquele e não como uma conquista histórica dos setores populares da sociedade. Dessa maneira, os espaços de participação passam a ser regulados pelas formas de concessão, e os terrenos para o diálogo são previamente preparados para favorecer os interesses dos setores que definiram a concessão. Essa tem sido uma prática adotada em tempos de crise (política, social, ambiental), como maneira adotar, com o aparente apoio popular, medidas que, muitas vezes, representam muito mais o interesse dos setores dominantes (SANTOS e SAITO, 2013).

Outro aspecto desse processo de mitificação se refere à noção de igualdade entre os segmentos participantes do processo. Aqui se chama a atenção para o fator de mitificação através do qual se apresenta a crença de que os grupos que participam das negociações e tomada de decisões no comitê de bacia hidrográfica têm as mesmas condições de participar e contribuir em tal processo. Nesse caso, a mitificação da participação se dá por ignorar a assimetria de poder econômico, de conhecimento técnicocientífico, de eloquência na fala e de poder de argumentação, existentes entre os diversos segmentos sociais envolvidos (SANTOS e SAITO, 2013).

Por fim, o terceiro aspecto diz respeito ao caráter do resultado obtido pelos processos de participação, isto é, a solidificação da cultura de consumo e da acumulação de capital, ambos diretamente correlacionados ao primeiro aspecto da mitificação. Particularmente na gestão dos recursos hídricos, esse aspecto da mitificação, se evidência na medida em que os "processos participativos em curso são direcionados para a qualificação da água como um bem privado, desqualificando as lutas históricas de acesso à água e sua caracterização como bem público" (SANTOS e SAITO, 2013, p. 15).

Os mecanismos determinados na Lei das Águas, que remetem à participação e controle social, por mais que pareçam legítimos, sejam assegurados legal e institucionalmente pela lei, e se constituam em um avanço no processo democrático descentralização no poder central do Estado, na prática se configuram como um instrumento do Estado para manipular o processo de participação e alienar a sociedade civil para convergir com as decisões tomadas pelo poder central. Isso coaduna com a ideia de Teixeira (2001) que ensina que muitas vezes esses mecanismos são criados para camuflar as contradições da ideologia dominante.

Analogamente pode-se associar a esse pensamento o fato de o Estado determinar a política das águas como descentralizada e determinar a limitação desse poder na própria lei. Ou seja, quem regula o nível de participação é o próprio estado ao delimitar o poder e os espaços que esses mecanismos atuarão.

O que se ressalta, aqui, não é a ideia de que o Estado não acompanhe ou regule essas ações, mas o fato de o mesmo determinar até em que nível pode haver a participação, e o alcance das decisões limita os cidadãos em buscar alternativas que abarquem os anseios locais e assegurem que as suas necessidades sejam alcançadas. Com esse poder limitante como prevenir que governos estabeleçam acordos como grupos econômicos para garantir os seus interesses em detrimento do interesse coletivo? Há indícios dessa ocorrência, por exemplo, com as outorgas do direito de uso das águas que estão sendo concedidas pelo governo do estado da Bahia sem que sejam discutidas nos Comitês de Bacias Hidrográficas. 


\section{A PARTICIPAÇÃO NOS COMITÊS DE BACIA E A ESCADA DE PARTICIPAÇÃO}

A escada de Arnstein (2002) pressupõe uma elevação do grau de participação a partir do envolvimento dos sem nada, aquele grupo que geralmente reivindica participação pela negação do Estado e da sociedade, absorvendo maior conhecimento, o que the permite crescer e buscar mais espaço e poder. Esta participação pode ser limitada pelo poder central enquanto o mesmo tiver condições de alienar os participantes, conduzindo-os a seguir a política pré-estabelecida e guiando-os para a aceitação do que for por ele determinado. Assim o grupo social tem a ilusão de que estão participando do processo decisório e da formulação das políticas públicas, quando estão apenas validando ou referendando as determinações do poder central. Essas condições são aludidas na Escada de Arnstein (2002) nos primeiros degraus.

A partir das categorias elencadas nessa escada de participação, é possível inferir que no contexto da gestão dos recursos hídricos no Brasil não há uma evolução de participação social visto que a Lei das Águas, de certa forma, limita esse poder de participação com os mecanismos que nela estão propostos. Ou seja, esse poder está limitado na forma da Lei e o degrau de envolvimento ao qual os agentes podem chegar ao debate sobre os recursos hídricos no espaço determinado pelo comitê de Bacia é o degrau da pacificação.

$\mathrm{Na}$ visão de Arnstein (2002), nessa etapa os participantes começam a ter certo grau de influência, ainda que limitado. No caso dos comitês de bacias hidrográficas na Bahia ainda é o Estado que determina a política hídrica e os comitês não são envolvidos em etapa alguma, nem mesmo para que sejam discutidos os ditames desta política. Não foi possível observar que o comitê seja atuante enquanto arena de poder compartilhado, visto que não constam em atas discussões sobre aspectos e competências dos comitês de bacias, apenas mediações sobre processos administrativos internos.

Por mais que os poderes dos comitês sejam limitados pela lei das Águas, a escolha dos membros para compor esses conselhos na qualidade de representantes da sociedade civil e dos usuários da água é feita de forma aleatória ou política. Esses participantes não são efetivamente insurgentes de movimentos populares e militantes na área ambiental, ou, ainda, os "sem nada" conforme conceituado por Arnstein (2002). Geralmente a escolha do representante é política.

Essas pessoas são escolhidas de forma tão aleatória que o próprio comitê fornece um curso de capacitação aos novos integrantes para entenderem a Política Nacional de Recursos Hídricos e as competências dos comitês de bacias. A depender do usuário de água que ministre esse curso, a forma de alienação pode começar nessa etapa. As informações repassadas podem ser escolhidas superficialmente para alienar o novo participante de forma que ele adira ideologicamente à lógica desse comitê, não lhe permitindo o debate e os questionamentos acerca das deliberações que são da competência do comitê. Um exemplo desta situação são os argumentos por vezes utilizados no intuito de dificultar a implementação do Plano de Recursos Hídricos e cobrança pelo uso da água, evitando, assim, dificultar interesses econômicos de usuários de água de determinada bacia.

Outro indicativo de que a política de recursos hídricos ainda é ditada pelo governo do estado e que os representantes da sociedade civil permanecem na inércia, reside no fato de que desde 2009 não foi criado outro comitê de bacia hidrográfica na Bahia, mesmo com o estado tendo 26 Regiões de Planejamento e Gestão das Águas - RPGAs (INEMA, 2014). Dentre os 14 comitês criados, apenas três iniciaram os projetos de implementação dos planos de recursos hídricos e ainda estão distantes da implementação da cobrança pelo uso da água.

QUADRO 04 - Panorama do estado da Bahia

\begin{tabular}{|c|c|c|c|c|}
\hline Comitês & Ano & Plano de recursos Hídricos & $\begin{array}{c}\text { Cobrança do uso da } \\
\text { Água }\end{array}$ & Agências da Água \\
\hline $\begin{array}{c}\text { Itapicuru, Leste, Paraguaçu, } \\
\text { Recôncavo Norte e } \\
\text { Inhambupe, Verde/Jacaré, } \\
\text { Salitre, }\end{array}$ & 2006 & $\begin{array}{c}\text { Em andamento os Planos de } \\
\text { recursos hídricos no Comitê do } \\
\text { Leste, Recôncavo Norte } \\
\text { Inhambupe e da Bacia do } \\
\text { Paraguaçu. }\end{array}$ & Não foi implementado & Não foi implementado \\
\hline $\begin{array}{c}\text { Contas, Corrente, Grande, } \\
\text { Sobradinho, }\end{array}$ & 2008 & Não foi implementado & Não foi implementado & Não foi implementado \\
\hline $\begin{array}{l}\text { Frades, Buranhém e Santo } \\
\text { Antônio, Peruípe, Itanhém e } \\
\text { Jucuruçu, Recôncavo Sul, } \\
\text { Parimirim e Santo Onofre }\end{array}$ & 2009 & Não foi implementado & Não foi implementado & Não foi implementado \\
\hline
\end{tabular}




\section{CONCLUSÃO}

A Lei ํㅜ 9.433/97 imprimiu mudanças consideráveis no setor de recursos hídricos brasileiro ao definir um modelo descentralizado e a participação nas decisões instituindo comitês de bacia hidrográfica como responsáveis por esta gestão. Este modelo inspirado na experiência francesa de gestão de recursos hídricos e de saneamento parece funcionar bem na França e em vários outros países que o adoraram, mas tem fragilidades e dificuldades no contexto brasileiro. Essas dificuldades encontram-se tanto no plano operacional, de funcionamento dos comitês, quanto no plano social e politico, no exercício real do processo participativo. No plano operacional pode ser apontada como problema a própria formação dos comitês:

No que tange ao processo de participação e de representação, dois fatores contribuem para que esta participação da sociedade, em alguns dos comitês, seja incipiente: o distanciamento entre os locais de conflito, em torno dos usos dos recursos hídricos e a indicação dos mobilizadores regionais sem o perfil adequado para atuarem nos comitês. Essa segunda dificuldade abre espaço para a alienação desses participantes e a consequente manipulação dos mesmos nas tomadas de decisão.

O que se percebe como grau de participação da sociedade nesses comitês, a partir da escada estabelecida por Arnstein (2002) é que esta participação tem sido limitada pelo poder central ficando circunscrita aos primeiros degraus da escada, podendo o envolvimento dos participantes chegar, no máximo, ao degrau da pacificação, com certo grau de influência, mas ainda limitado. Enfim, a política de recursos hídricos é ditada pelo governo do estado e os representantes da sociedade civil não conseguiram, ainda, criar o seu espaço de participação efetiva. Esses comitês existem, apenas, em um nível institucional formalizado, mas sem a força necessária para possibilitar uma descentralização da gestão dos recursos hídricos e uma maior aderência da sociedade civil.

\section{REFERÊNCIAS}

ABERS, Rebecca; JORGE Karina Dino. Descentralização da gestão da água: Por que os comitês de bacia estão sendo criados? Ambiente \& Sociedade - Vol. VIII no. 2 jul./dez. 2005, p. 1-26.

ANA. http://www.ana.gov.br/GestaoRecHidricos/articulacaolnstitucional/16/04/2011

ARNSTEIN, Sherry R. A Ladder of Citizen Participation. Journal of the American. Institute of Planners. XXXV, 1969. pp.: 216-224.

ARNSTEIN, Sherry R. Uma escada da participação cidadã. Revista da Associação Brasileira para o Fortalecimento da Participação - PARTICIPE, Porto Alegre/Santa Cruz do Sul, v. 2, n. 2, p. 4-13, jan. 2002. http://geocities.yahoo.com.br/eridiane

AVRITZER, Leonardo. Modelos de sociedade civil: uma análise da especificidade do caso brasileiro. In: MITRE, Antonio (org.). Ensaios de teoria e filosofia política. Belo Horizonte: DCP/UFMG, 1994.

BAHIA. Lei $\mathrm{n}^{\circ}$ 10.432, de 20 de dezembro de 2006 . Disponível em: http://www.semarh.ba.gov.br/Legislacao/Leis\%20Estaduais/Lei10432.pdf. Acessado em 29.09.2011.

BARRAQUÉ Bernard. As Políticas da Água na Europa. Instituto Piaget: Portugal, 1996

BERRETA, Márcia dos Santos Ramos. Gestão democrática das águas: os desafios à participação dos agricultores da bacia hidrográfica do Arroio Ribeiro, RS. 2013. 256 f. Tese (Doutorado) - Curso de Programa de Pós-graduação em Geografia, Departamento de Instituto de Geociências, Universidade Federal do Rio Grande do Sul, Porto Alegre, 2013. Disponível em: <http://hdl.handle.net/10183/77989>. Acesso em: 03 ago. 2014.

BEZERRA e SILVA, Francisco Carlos (org.). Fórum Nacional de Comitês de Bacia Hidrográfica. Reflexões e Dicas: para acompanhar a implementação dos sistemas de gestão de recursos hídricos no Brasil. Brasília: WWF - Brasil/FNBCH, 2005.

BOBBIO, Noberto. Estado, Governo e Sociedade. Rio de Janeiro: Paz e Terra,1985.

BORDENAVE, Juan E, Díaz. O que é participação. São Paulo: Ed. Brasiliense, 1994.

CBH (COMITÊS DE BACIAS HIDROGRÁFICAS) http://www.cbh.gov.br

COUTINHO, C. N. Hegel e a democracia. Conferência apresentada no Instituto de Estudos Avançados da Universidade de São Paulo, em 13 de junho de 1997.

COUTO, B. R. O Direito Social e a Assistência Social na Sociedade Brasileira: uma equação possível? São Paulo: Cortez, 2004.

DAGNINO, Evelina (Org) Sociedade Civil e Espaços Públicos. Editora Paz e Terra, São Paulo, 2002.

FADUL, E. M. C; SILVA, L. P.; CERQUEIRA, L. S. . Reflexões sobre o modelo de gerenciamento de recursos hídricos de por comitês de bacias hidrográficas. In: XXXV Encontro da ANPAD, 2011, Rio de Janeiro. XXXV Encontro da ANPAD. Rio de Janeiro : Associação Nacional de Pós-Graduação e Pesquisa em Administração, 2011.

FADUL, Elvia M. C. e MUNIZ, Reynaldo Maia. Contradicciones em um proceso democrático: la práctica del presupuesto 
participativo em las ciudades brasileñas. Revista del CLAD Reforma y Democracia. No. 18 (Oct. 2000). Caracas, p. 1-13. FADUL, Élvia; NUNES, E. A. Recursos Hídricos e Participação: os Comitês de Bacias Hidrográficas constituem uma nova forma de exercício do poder pelo cidadão?. In: XXXVIII EnANPAD - Encontro Científico de Administração, 2014, Rio de Janeiro. Anais do XXXVIII EnANPAD. Rio de Janeiro: Associação Nacional de Pós-Graduação e Pesquisa em Administração - ANPAD, 2014. v. 2.

FADUL, Élvia; SILVA, Lindomar Pinto da; CERQUEIRA, Lucas Santos. Políticas e gestão de recursos hídricos por comitês de bacias hidrográficas: uma análise do Comitê de Bacia Hidrográfica do Recôncavo Norte e Inhambupe. Bahia Analise \& Dados, v. 23, p. 409-423, 2013.

FADUL, Élvia; SILVA, Lindomar Pinto da; CERQUEIRA, Lucas Santos . Reflexões sobre o modelo de gerenciamento de recursos hídricos por comitês de bacias hidrográficas. In: Encontro da Associação Nacional de Pós-Graduação e Pesquisa em Administração, 2011, Rio de Janeiro. Anais do XXXV Encontro da Associação Nacional de Pós-Graduação e Pesquisa em Administração. Rio de Janeiro: ANPAD, 2011. v. 1.

GOHN, Maria da Glória Empoderamento e participação da comunidade em políticas sociais. Saúde e Sociedade v.13, n.2, p.20-31, maio-ago 2004

HAASE, Janine. O Encontro Estado e Sociedade na Política Gaúcha das Águas. Tese de Doutorado, Departamento de Ecologia, UFRGS. Porto Alegre, RS. 2005

HABERMAS, J. 1997. Direito e democracia: entre facticidade e validade. Rio Janeiro: Tempo Brasileiro. v. 2.

HAGUETTE, Tereza Maria Frota. O Cidadão e o Estado: A Construção da Cidadania Brasileira, 1940-1992. Fortaleza: Edições UFC, 1994.

INGÁ. http://www.inga.ba.gov.br/modules/pico/index.php?content id=30. Acessado em 14.04.2011

JACOBI, Pedro. Políticas Sociais e a Ampliação da Cidadania. 2ª edição. Rio de Janeiro: Editora FGV, 2002.

JELIN, E. Cidadania revisitada: Solidariedade, Responsabilidade e Direitos. In: JELIN, E.;HERSHBERG, E. (Orgs.). Construindo a democracia: direitos humanos, cidadania e Sociedade na América Latina. São Paulo: Edusp, 2006.

KISSLER, Leo e HEIDEMANN, Francisco G. Governança pública: novo modelo regulatório para as relações entre Estado, mercado e sociedade? RAP Rio de Janeiro 40(3):479-99, Maio/Jun. 2006

MARCO, Thomás A. Sancho, Aspectos financieros de La Gestión del Agua: El caso de lacuencadel Ebro, in III Assembléia Geral da Rede Internacional de Organismos de Bacia (RIOB), Salvador, dezembro 1998.

MILANI, Carlos. O princípio da participação social na gestão de políticas públicas locais: uma análise de experiências latino-americanas e europeias. RAP, Rio de Janeiro 42(3):551-79, maio/jun. 2008.

MINAYO, Maria. C. S. Ciência, técnica e arte: o desafio da pesquisa social. In: MINAYO, Maria. C. S (Org.). Pesquisa social: teoria, método e criatividade. Petrópolis, RJ: Vozes, 2001. p.09-29.

MORAIS, José L. M., Gestão de recursos hídricos por comitês de bacias hidrográficas: limites e desafios na implementação do modelo nos estados do Nordeste. Dissertação de Mestrado. Programa de Pós-graduação em Administração. Mestrado em Administração. Universidade Salvador, Salvador, 2012.

MORAIS, José Luciano Mendonça ; FADUL, Élvia ou CAVALCANTI FADUL, E. M. Limites E Desafios Na Gestão De Recursos Hídricos Por Comitês De Bacias Hidrográficas: Um Estudo Nos Estados Do Nordeste Do Brasil. In: Iberoamerican Academy of Management, 2013, São Paulo. Proceedings of the Iberoamerican Academy of Management. São Paulo: FGV, 2013.

NOGUEIRA, M. A. Um Estado para a sociedade civil: temas éticos e políticos da gestão democrática. São Paulo: Cortez, 2004, p. 130 - 133.

PNRH. Lei no 9.433. Política Nacional de Recursos Hídricos. Brasília: Secretaria dos Recursos Hídricos, Ministério do Meio Ambiente, dos recursos Hídricos e da Amazônia Legal, 1997.

PUTNAM, R. Comunidade e democracia: a experiência da Itália moderna. $2^{\text {a }}$ edição. Rio de Janeiro, FGV, 2000.

SANTOS, Irenilda Ângela dos; SAITO, Carlos Hiro. A mitificação da participação social na política nacional de recursos hídricos: gênese, motivação e inclusão social. Geosul, Porto Alegre, v. 21, n. 42, p.7-27, jun. 2006. Disponível em: <https://periodicos.ufsc.br/index.php/geosul/ article/download/12810/11993>. Acesso em: 02 ago. 2014.

SANTOS, M. E. P. As Águas como Direito e como Commodity - Uma Contradição em Termos? RDE. Revista de Desenvolvimento Econômico, Salvador, Bahia, v. IV, n. 6, p. 60-70, 2002.

SILVA, S. C Sociedade civil e poder local: participação nos conselhos municipais gestores de políticas públicas para a ampliação do debate do desenvolvimento local.

SOUZA JUNIOR, Wilson C. Gestão das Águas no Brasil: Reflexões, Diagnósticos e Desafios. São Paulo: Petrópolis, 2004.

TEIXEIRA, E. Celso. O local e global: limites e desafios da participação cidadã. $2^{\underline{a}}$ ed. São Paulo: Cortez: Recife: EQUIP; Salvador: UFBA, 2001 